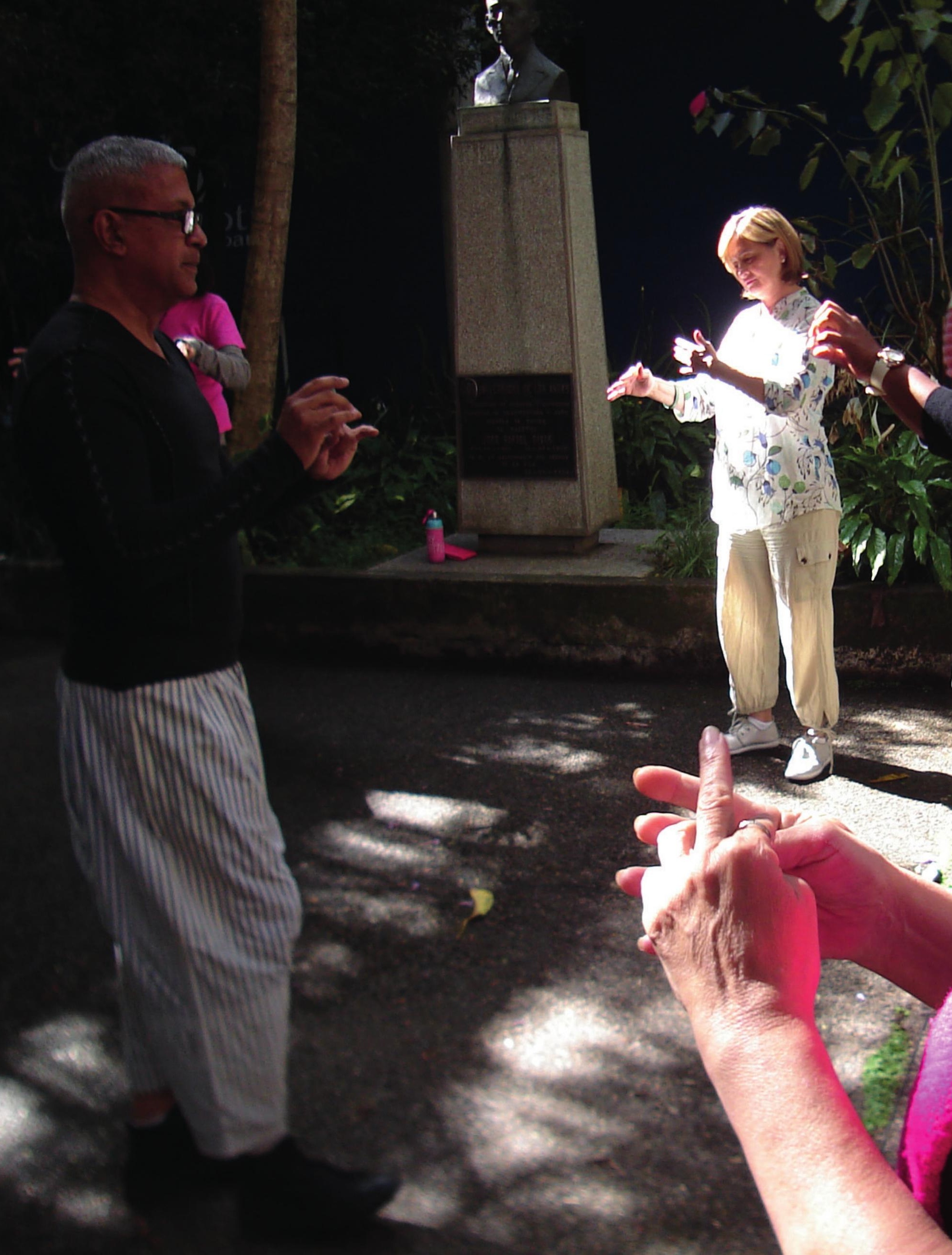




\section{Laboratorio del juego. Espacio formativo de Juego escénico para el reemprendimiento y libertad}

\author{
Artículo de investigación artística \\ Recibido: 27 de noviembre de 2020 \\ Aprobado: 19 de junio de 2021 \\ Igor Raphael Martínez Rebolledo \\ Universidad de Los Andes, Venezuela. \\ martinezigor1@gmail.com
}

Cómo citar este artículo: Martínez Rebolledo, Igor Raphael (2022). Laboratorio del juego. Espacio formativo de Juego escénico para el reemprendimiento y libertad. Estudios Artísticos: revista de investigación creadora, 8(12) pp. 62-77. DOI: https:// doi.org/10.14483/25009311.18764

$<$

Registro de procesos (2021). Fotografía: Rossana Toro.

\section{(c) (i)}

https://creativecommons.org/licenses/by/4.0/deed.es

\section{Resumen}

El artículo expresa el proceso y resultados de la primera fase de: "El laboratorio del Juego"; un proyecto de investigación comunitario desarrollado en el mes de julio del año 2019, dirigido a doce adultos mayores de la Parroquia Sagrario, municipio Libertador de la ciudad de Mérida, Venezuela, con el propósito de promover "el juego" como forma de autoreconocimiento y reemprendimiento desde cuatro estadios de representación: percepción, imaginación, comunicación y expresión. La investigación siguió el paradigma cualitativo y se desarrolló bajo el enfoque introspectivo vivencial, la metodología aplicada fue la participación acción y la sistematización se obtuvo por medio de la técnica de la observación participativa lo que viabilizó la codificación e interpretación de la experiencia a partir del método de comparación constante. Esta fase arrojó resultados orientados al redescubrimiento de posibilidades expresivas tras vivenciar el juego y reconocimiento de las potencialidades humanas para emprender nuevos proyectos de vida.

\section{Palabras clave}

Investigación pedagógica; juego educativo; educación comunitaria; psicología social; artes escénicas

\section{Game Lab. A training space for stage games aimed at re-entrepreneurship and freedom}

\section{Resumen}

This article presents the process and results of the first phase of "The Game Lab", a community research project developed in July 2019, involving twelve senior citizens from the Sagrario parish, in the Libertador municipality of the city of Mérida, Venezuela. It had the purpose of promoting "play" 
as a form of self-recognition and re-entrepreneurship, using four stages of representation: perception, imagination, communication and expression. Our research followed a qualitative paradigm and it was developed under an experiential-introspective approach. We used a methodology of applied participation/action and its systematization was carried out through participatory observation, which made possible the coding and interpretation of the experiences from a constant comparison of the data. This phase resulted in the rediscovery, by the participants, of expressive possibilities derived from their experience of play and the recognition of human potentialities that allow undertaking new life projects.

\section{Palabras clave}

Andar; cotidianidad; errante; paisaje; vagabundeo

\section{Laboratoire de jeu. Un espace de formation en jeux théâtraux destiné au ré-entrepreneuriat et à la liberté}

\section{Résumé}

Cet article présente le processus et les résultats de la première phase du «Laboratoire de jeu », un projet de recherche communautaire développé en juillet 2019, impliquant douze personnes âgées de la paroisse de Sagrario, dans la municipalité Libertador de la ville de Mérida, Venezuela. Le but de promouvoir le « jeu » comme une forme de reconnaissance de soi et de ré-entrepreneuriat en utilisant quatre étapes de représentation : perception, imagination, communication et expression. Notre recherche a suivi un paradigme qualitatif et il a été développé sous une approche expérientielle-introspective. Nous avons utilisé une méthodologie de participation/action appliquée et la systématisation a été réalisée à travers l'observation participative, qui a rendu possible le codage et l'interprétation des expériences à partir d'une comparaison constante des données. Cette phase a abouti à la redécouverte, par les participants, de possibilités expressives dérivées de l'expérience du jeu et de la reconnaissance des potentialités humaines qui permettent aussi d'entreprendre de nouveaux projets de vie.

\section{Mots clés}

Recherche pédagogique ; jeu éducatif ; éducation communautaire ; psychologie sociale ; spectacles vivants

\section{Laboratório do jogo. Espaço formativo de Jogo cênico para o reempreendedorismo e liberdade}

\section{Resumo}

O artigo expressa o processo e os resultados da primeira fase de: "El laboratorio del Juego"; um projeto de investigação comunitária desenvolvido no mês de julho do ano de 2019, dirigido a doze adultos idosos da Paróquia Sagrario, no município de Libertador da cidade de Mérida, Venezuela, com o propósito de promover "o jogo" como forma de auto reconhecimento e reempreendedorismo a partir de quatro estágios de representação: de percepção, imaginação, comunicação e expressão. A investigação seguiu o paradigma qualitativo e se desenvolveu a partir do enfoque introspectivo vivencial, a metodologia aplicada foi a participação ação e a sistematização se obteve por meio da técnica da observação participativa, o que viabilizou a codificação e interpretação da experiência a partir do método de comparação constante. Esta fase agregou resultados orientados para o redescobrimento de possibilidades expressivas a partir da vivencia do jogo e reconhecimento das potencialidades humanas para empreender novos projetos de vida.

\section{Palavras chave}

investigação pedagógica; jogo educativo; educação comunitária; psicologia social; artes cênicas

\section{Pugllapa iachaikudiru maipi iachachii pugllapa kawachingapa llauti rurai kallarispa imasa munaskasina}

\section{Maillallachiska}

Kai mailla kilkaipi kawachiku imasami pai kallarispa ruraii "iachachidiru pugllaspa" sug apachii kallariska tapuchi kai watapi, julio 219, kai kaskami chunga iskai atun kunamanda parroquia sagrada sutimanda kunata kausaskakuna libertador sutipi atun llagta Mérida sutipi Venezuelapa achachingapa "imasa 
pugllai" nukanchi kikin kausaskata kawangapa ikuti kallarispa kai chusku kallarikunaua iuiarii, parlai, kawagsina. Ruraska, kai tapuchii apamunakuska ñugpamandata imasami ka kausaikuna chasallata kai kami ministidu iachangapa masami chanchi chasallata kanchama kawachingapa mana kanchichu sugkunasina.

Chasa kaipi nispa niku tariskakunasi suma ruraikuna ikuti kausachispa apachingapa kati kausaita pugllaspa. Kawaspa maitukum pudinchi ruranga imakuna nukanchi chasa ikuti ñugpasinamanda kausaikuna katichingapa.

\section{Rimangapa Ministidukuna}

Tapuchispa iachachingapa; pugllaspa iachachingapa; iachachi ñima chaskispalla; iacha aidachidur; ruraskata kawachidur

\section{Introducción}

Cuando se habla de "juego" se refiere a un estado de expresión por medio del cual el individuo tiene la posibilidad de incorporarse a una realidad que rompe con la cotidianidad de la existencia. Es un espacio único que, no solamente se presenta como una experiencia que posibilita el desarrollo de capacidades y competencias a favor de la participación social, sino que abre la puerta a un momento de libertad único desde donde los seres humanos se proyectan con mayor autenticidad, siendo ellos mismos en su individualidad. Se trata de una práctica que es sinónimo de despertar del poder imaginario por lo que se vive un momento de lo posible que no da cabida a las circunstancias inaccesibles de la realidad. Para Caillois (1986):

(...) el juego se debe definir como una actividad libre y voluntaria, como fuente de alegría y de diversión... el jugador se entrega a él espontáneamente, de buen grado y por su gusto, teniendo la total libertad de preferir el retiro, el silencio, el recogimiento, la soledad ociosa o una actividad fecunda. (pp. 3-4)

Y es que "el juego" tiene que ver con una historia no contada del individuo, en la que recrea todo su conocimiento acerca de la comprensión del mundo que le rodea y la proyección de ese "universo" transformado por el imaginario hacia la proyección de un mundo mejor donde se hace protagonista. Es un acto falso por cuanto el individuo juega, simula una realidad paralela a lo real, pero es verdadero por cuanto lo vivencia con el poder de su existencia con tal vehemencia que lo convierte en verdad absoluta. De allí el poder que tiene "el juego" infantil, no sólo como plataforma única para generar nuevos conocimientos en el niño y como excusa para diagnosticar su contexto y su realidad física y emocional, sino también como proyección de la realidad próxima, pues desde muy temprana edad el ser humano, en situaciones de juego, recrea lo que será su vocación y desempeño futuro.

En el contexto de "el juego", el individuo es capaz de llegar a transformar su corporeidad, al modificar, entre otros aspectos, su corporalidad, es un proceso en el que se internaliza un carácter que conduce a una transformación de la persona a otra. Cuando un niño o niña juega a ser "el monstruo" se cree, construye, vive el ser ese monstruo desde todo su potencial, no sólo se transforma físicamente, lo hace emocionalmente, construye una imagen que desea proyectar para sí, y busca atemorizar a los demás con su construcción imaginaria a la que ha insertado toda su organicidad, lo que incluye su proceso imaginativo y todos los vehículos que le posibiliten inducir temor en otros en la representación de su juego. Este asunto al que Caillois (1986) denomina la categoría "Mimicry", interpreta a "el juego" como una acción que:

(...) supone la aceptación temporal, sino de una ilusión (aunque esta última palabra no signifique entrada al juego; in-(usio), cuando menos de un universo cerrado convencional y, en ciertos aspectos, ficticio. El juego puede consistir, en desplegar una actividad o en soportar un destino en un medio imaginario, sino en ser uno mismo un personaje ilusorio y conducirse en consecuencia. (p. 52)

Un proceso en el que el individuo en juego deja de ser sí mismo para encarnar a otro, lo que en la representación dramática o en el teatro se podría denominar "juego escénico" y que es parte del trabajo del intérprete actoral. Un espacio en el que el actor, desde su corporeidad "edifica" a un personaje cuyas características físicas, psicológicas, históricas, contextuales, en sus necesidades, entre otros aspectos, no tiene que ver con su existencia, pero para lo que se dispone a construir como un suceso creativo y a disposición del drama, un 
acto de juego escénico que resulta falso dado que se trata de una representación, pero que está constituido con verdades humanas. De allí que lo que hace el intérprete actoral es construir lo que a juicio de Gelvis (2017), se entiende de la "mímesis" aristotélica:

(...) un arte de imitación. Lo que se imita son las acciones del hombre (...) desde la representación de modo directo, el cual se hace con medios y objetos idénticos buscando lo más cercano a lo que se está imitando, es decir, se busca una reproducción lo más parecida al modelo original. (p. 7)

Para construir desde "el juego", los seres humanos amplían su capacidad de percepción, de hacer, moverse de un lado al otro, lo que convierte a "el juego" en un espacio generador de placer, de importantes desafíos y de poder imaginario, de movimiento constante donde lo significativo no son el principio ni el fin de "el juego" sino el transcurso, en el yo, de allí que Huizinga entienda "el juego" como una: "acción que tiene su fin en sí mismo y que va acompañado de un sentimiento de tensión y alegría y de la conciencia de "ser de otro modo" que en la vida corriente" (pág. 46). Es por ello que las acciones lúdicas son prácticas que fortalecen las virtudes humanas que pueden llegar a generar en el individuo las capacidades para reflexionar acerca de las acciones de su vida, sus perspectivas, hacer una evaluación de su existencia y sobre aquellas experiencias y emociones que le generan bienestar y mayor conciencia acerca de sus capacidades y logros.

Es por ello que "el juego" constituye una plataforma para el desarrollo de competencias, porque las personas aprenden a contextualizar sus decisiones y acciones a seguir, por lo que cimentan proyectos para el futuro, lo que significa transformar la realidad en espacios en donde se fluye con libertad y autonomía, en donde se pueden recrear nuevos mundos visualizando grandes proyectos para la realidad futura, por lo que, en el caso del individuo adulto, la práctica de jugar le hace capaz de reemprender inmerso en un sentimiento de liberación y exteriorización de las emociones tras haber emprendido ya en su juventud, abriéndose ahora a nuevas sensaciones, a un despertar de la sensibilidad que se fue durmiendo en el camino a la madurez, percibiendo de manera diferente el aquí y el ahora a como se entendía antes de la práctica de juego.

Se trata pues de un cambio en las expectativas humanas que incluye el reconocimiento de las fortalezas, aspecto fundamental que se corresponde con lo planteado por la psicología positiva como forma de autenticidad. Seligman (2006) en relación a la relevancia de emplear las fortalezas, manifiesta lo siguiente en su libro "La auténtica felicidad":

El bienestar que genera el empleo de las fortalezas propias radica en la autenticidad. Pero al igual que el bienestar necesita arraigarse en las fortalezas y virtudes, éstas a su vez deben arraigarse en algo superior. Del mismo modo que la buena vida es algo más que la vida placentera, la vida significativa es algo más que la buena vida. (p. 10)

Son estas reflexiones las que anteceden y dan origen al laboratorio del juego, una investigación de orden comunitario acerca de la relevancia del juego escénico y su incidencia en el adulto mayor. Una experiencia que se encamina sobre la comprensión de "el juego" como expresión institintiva del comportamiento humano a partir de una serie de acciones que proponen abrir la puerta a un universo donde la lúdica ofrece espacios para crear, identificarse con otros, ser cada quien y proyectarse hacia la generación de espacios de transformación social para el futuro.

\section{Marco Teórico de la Investigación}

\section{"La actualidad de lo bello" Hans - Georg Gadamer}

Hans - Georg Gadamer (1900 - 2002) en su obra:

"La actualidad de lo bello" hace gala de un puente ontológico entre la tradición clásica del arte de la antigüedad y el arte moderno. Lo hace desde la modernidad, por lo que somete al arte de la antigüedad a una especie de análisis orientado desde interrogantes que se han ido produciendo en la modernidad. Su lucha se entabla a partir de los preceptos de que el arte es también conocimiento, idea planteada en contraposición de otros filósofos que han argumentado la preeminencia del valor estético en el arte por encima del valor social y la cognición que rodea a la obra. Para ello establece una especie de "viaducto", tal y como lo expresa Argullol (1991) en la introducción de la 
primera edición de su libro publicado en 1991 en el que plantea que "...El puente al que aludimos se convierte, en cierto modo, en un doble puente: el que debe unir lo antiguo a lo moderno y el que debe facilitar la circulación entre la filosofía y el arte" (p. 6).

Para Gadamer la práctica del culto tiene un componente lúdico y es que el juego establece reglas que necesariamente se componen de espacio, intención, proporción, medidas, reglas sistematizadas del acto de juego, pues se tratan de una construcción que tiene un propósito y una razón de ser en la vida humana. Toda actividad humana que implique trabajo está normada por lo que establecer una dicotomía juego - trabajo no tendría sentido alguno, aunque la presencia del juego en el desarrollo humano está íntimamente ligada a su actividad cultural, entiéndase la representación, la belleza, lo místico, el arte entre otras, en todas sus manifestaciones y por supuesto lo sagrado. De allí que Gadamer se detenga en este concepto como una presencia oculta y poderosa que representa un espacio de auténtica libertad en los seres

El juego aparece en la existencia como un movimiento propio que no se orienta hacia el final o a la meta de un propósito, sino a un movimiento constante o un fenómeno de autorrepresentación del ser viviente. Para Lorca (2005) “El verdadero sujeto en juego, entonces, es el juego mismo, que atrae a quienes participan en él y los sumerge en su realidad lúdica, realidad que los jugadores experimentan como una realidad que los supera" (p. 7). En el juego entonces hay una pugna, hay intención, emoción, tensión, expectativa, ansiedad, necesidad, todo ello porque está vivo y ese constante repetir es un impulso de automovimiento que se conduce al movimiento mismo por lo que se genera, como él mismo lo dice: "...una conducta libre de fines, pero esa conducta misma es referida como tal".

\section{La teoría del juego de Johan Huizinga}

Para Huizinga (1938) "el juego" es un modo que:

"...está concebido como una función humana tan esencial como la reflexión...". (p.6) una expresión en la que el individuo expresa sus saberes desde lo que conoce, pero también desde lo desconocido e inexplorado porque se trata de un proceso que también incluye a la imaginación, una función llena de sentido. El juego es una acción u ocupación libre, que se desarrolla dentro de unos límites temporales y espaciales determinados, según reglas absolutamente obligatorias, aunque libremente aceptadas, acción que tiene su fin en sí misma y va acompañada de un sentimiento de tensión y alegría y de la conciencia de "ser de otro modo" que en la vida corriente. (Huizinga, 1938, p. 46).

Es así como se refiere al juego como un espacio en el que el participante se somete a reglas, tal y como sucede en la escena teatral donde el jugador confronta la posibilidad de que otros participen del juego, aportando al proceso de su vivencia y conocimiento en un espacio donde el trabajo en conjunto establece relaciones de cooperación, de allí que como asevera Ríos (2012):

Huizinga nos quiere dar a entender que en el juego se dan dos fenómenos: el de la broma (no serio) y lo serio del juego. Como broma ocupa un lugar inferior, pero como serio ocupa un lugar superior. Me parece que ambos serían los límites del juego y su ambigüedad constituyente. (p. 75)

De allí que en la visión de Huizinga que en "el juego" serio sea importante que se instituyan alianzas y acuerdos para crear y de espacios de indagación para lo que la experiencia engloba: improvisaciones, juegos de roles, animaciones, adaptaciones de textos, entre otros y donde se desarrollan diversas formas de expresión tales como: la lingüística, expresión corporal, coordinación rítmica, gesticulaciones, mímesis, entre otras.

\section{Roger Caillois y su teoría del juego}

Para Caillois (1986) "Todo juego es un sistema de reglas" porque es la regla la que sostiene el deseo de jugar y si esta es violentada ya no se está en juego. "La palabra juego evoca en fin una idea de amplitud, de facilidad de movimiento, una libertad útil, pero no excesiva, cuando se habla del juego de un engranaje o cuando se dice que un navío juega sobre su ancla" (p. 12). El juego es libertad y se concibe como un espacio en el que el individuo ejercita sus competencias ideales, ahora bien, no todo juego responde a la misma necesidad, es propio el espacio de juego en la existencia de cada persona por lo que los senderos que pueden recorrerse en la experiencia, si bien pueden llegar a ser afines en cuanto a las pretensiones naturales de 
los seres humanos, responderá como un universo único que pertenece a cada ser humano.

Ningún juego es tal si se está obligado a participar, lo que lo hace una práctica en la que el jugador se entrega espontáneamente por lo que es una ocupación que está aislada del resto de la existencia. "El juego" es una actividad incierta, se acompaña de la duda de cómo será el resultado, pero al igual que el inicio, esto no es de gran valor, son sus incidencias las que verdaderamente traen consigo el aprendizaje, el crecimiento como seres humanos, algo así como una puerta que cuando se abre ofrece capacidades de renovación constante, de inventar inmediatamente una respuesta que resulta libre dentro de los límites establecidos por las mismas reglas de juego.

Este puede definirse como una actividad libre, en cuanto el jugador participe sin obligatoriedad, separados porque se circunscribe a límites de espacio y tiempos precisos, incierto porque no puede vaticinarse un desenlace de la práctica, improductivo porque no genera bienes y riquezas, reglamentado porque se somete a convenciones que suspenden leyes ordinarias de la realidad y ficticia dado que se acompaña de una conciencia específica de una realidad secundaria que se escolta de procesos imaginativos.

\subsection{La psicología positiva a partir de las ideas de Martin Seligman}

La teoría de la psicología positiva no está enfocada hacia que el ser humano sea más optimista o espiritual o quizá amable, sino a las consecuencias que estos rasgos pueden generar en la vida de las personas. Su enfoque se orienta hacia el desarrollo de las potencialidades del ser humano y en el cómo este desarrollo puede hacer que lo que se proyecte concluya en metas exitosas, pues la orientación es hacia cómo hacer que las fortalezas y virtudes humanas sean utilizadas a favor propio $y$ común.

Martin Seligman propone en el año 2000 la Psicología positiva con el propósito de que la psicología se enfoque, no solamente en reparar las peores cosas de la vida, sino en la construcción de cualidades positivas y sus consecuencias. La psicología positiva se enfoca en la construcción de la felicidad a partir del uso de las potencialidades humanas o cómo lo expresa Jiménez (2011) “... Aportar una visión más completa del ser humano contemplando tanto las emociones negativas como las positivas con el fin de vivir una vida más plena, más comprometida sin perder de vista a la persona como individuo único e irrepetible". (p. 622).

Esta teoría no se basa en autoayuda, tampoco en solución a los problemas o terapia psicológica, lo que hay que tomar en cuenta es que es un camino para estudiar la salud mental efectiva siendo capaz el ser humano de manejarse positivamente hacia adentro y hacia afuera saliendo adelante con competencia, sintiéndose a gusto consigo mismo y aceptándose. De allí que la psicología positiva se enfoque hacia el equilibrio; anticipar y amortiguar, pero para alcanzarlo es necesaria la autonomía, vinculación y competencia, claves fundamentales para el alcance de una autoestima positiva. Otro aspecto relevante que proyecta la teoría es la coherencia y la forma en que las personas asumen positivamente la integración social, manera en que se adaptan al entorno con la justa claridad de las competencias que se poseen y la forma en que se aportará a determinada comunidad.

La psicología positiva está vinculada al emprendimiento, desde donde se fomentan las emociones positivas hacia el pasado, presente y futuro, estando activo y realizando actividades que permitan extraer aspectos positivos de cada persona, vinculados a lo que se realiza participando en proyectos que vayan más allá de las expectativas. Un espacio fundamental que se abre a la teoría es lo que se denomina la experiencia óptima; cuando el individuo realiza actividades en las que se ha planteado metas y acciones que son accesibles a sus capacidades y debe emprender la consecución de las mismas a partir del desempeño de sus potencialidades y capacidades de éxito. El estado de felicidad radica en la motivación e identificación plena con la actividad porque en la medida en que la meta representa una pasión para el individuo, en esa misma disposición enfrentará todos los obstáculos desde sus capacidades para la resolución de problemas que se vinculan con su potencial. 


\section{Propósito de la investigación}

El Laboratorio del juego se concibió como un espacio creativo y de libertad que tiene como punto de partida "la instintividad del juego de la infancia". Una manera de reconectarse con uno mismo, con la forma natural de jugar, autoreconocerse, reconocer al otro, entenderse y comunicarse con los demás. Por lo que se propuso una dinámica de trabajo experiencial de interrelación comunitaria dirigida a adultos mayores cuyas edades oscilan entre los 60 y 70 años, en la que los participantes vivenciaron una serie ejercicios de juego escénico orientados hacia el logro de potenciales conducentes a la pérdida del miedo escénico y el temor al fracaso. Un espacio para el autoreconocimiento en donde la improvisación corporal y la acción libre del juego es capaz de abrir la puerta a escenarios creativos en los que se pueden vivenciar momentos que contribuyen a generar espacios de relación con el colectivo y a hacer una contribución encaminada hacia procesos transformadores de la realidad.

\section{Objetivos de la investigación}

El Laboratorio del juego es un proyecto que se desarrolla por medio de una serie de fases de trabajo que contemplan aspectos tales como: el desarrollo de la percepción, el despertar de los procesos imaginativos, la importancia de la comunicación y la libre expresión a favor del reemprendimiento del adulto mayor en edad productiva. Esta primera fase o estadio introductorio estableció como objetivo general reflexionar acerca de una experiencia de participación comunitaria orientada en "el juego" como estrategia de expresión y comunicación dirigida a un grupo de adultos mayores de la Parroquia Sagrario, municipio Libertador de la ciudad de Mérida, Venezuela, para lo que se propusieron los siguientes objetivos específicos:

Establecer las acciones necesarias que posibiliten la incorporación de un grupo de adultos mayores de la comunidad centro, municipio libertador de la ciudad de Mérida, Venezuela, para formar parte de la experiencia de investigación. Ejecutar la primera fase de "el laboratorio del juego" con el grupo de personas seleccionadas en una práctica orientada al desarrollo de acciones de juego. Valorar el impacto de las acciones ejecutadas, tanto en el proceso formativo, como el reflexivo de los participantes. Sistematizar el proceso investigativo: práctica formativa, de acción participativa por medio de un registro de cuaderno de campo y en formato audiovisual, con el propósito de obtener información para ser codificada e interpretada para generar las reflexiones y reflexionar acerca de la investigación.

\section{Desplazamiento metodológico}

Un trabajo de investigación con estas características debía orientarse en el paradigma cualitativo debido a que su proceso implicaría el análisis de datos cualitativos en los que la experiencia en estudio era una sola, pero ante la realidad de que se trataba de una práctica en la que el desempeño fue grupal y que implicaba aspectos tales como: procesos imaginativos, comunicativos y de interrelación grupal, se hizo necesario centrarse en los ejercicios contenidos en las acciones y puntos de vista de cada uno de los participantes. Lo extraordinario fue llegar a dar significados a las incidencias expresadas en el registro informativo a pesar de que, en este tipo de investigación, la cual se sustenta en la conducta de los participantes, requieren de esfuerzos organizativos e interpretativos para dar significado a la experiencia, y que ese significado exprese a su vez, la sustancia de lo que se presentó en el momento en que se ejerció la acción. Tal y como lo enuncian Schettini y Cortazo (2015):

Cuando encaramos la tarea de analizar se produce en nosotros incertidumbre, desazón, angustia ya que se confrontan la interpretación de los sujetos, la comprensión del mundo simbólico (representado y organizado por el lenguaje) y de sus prácticas o acciones concretas. (p. 64)

Los pasos determinantes para llegar a este análisis partieron de la consideración de la instrospectiva vivencial, enfoque que como lo expresa Padrón (2001) se concibe como un: "producto del conocimiento que interpreta los simbolismos socioculturales a través de los cuales los actores de un determinado grupo social abordan la realidad (humana y social, fundamentalmente)" (p. 1). El grupo de participantes convocados para su primer 
encuentro el día 13 de julio de 2019, estaba constituido por 8 damas y 4 caballeros residentes de la comunidad de la Parroquia Sagrario, municipio Libertador de la ciudad de Mérida, estado Mérida, Venezuela.

En un conversatorio previo, realizado el día 11 de julio de 2019 a las 9:00am en la sede del edificio San José de la Universidad de Los Andes, el cual valdría como momento de encuentro para generar cercanía entre los participantes y de diagnóstico para conocer e identificar al grupo, se socializó acerca de las experiencias individuales dentro de su comunidad, todos manifestaron sentirse identificados con su contexto coincidiendo así en aspectos concernientes a las fortalezas y debilidades de su comunidad, tales como: problemas con los servicios de electricidad, agua y gas, falta de comunicación con sus líderes comunitarios, difícil acceso a la cesta básica de alimentos, buena comunicación entre vecinos, capacidad para trabajo en equipo, entre otros.

De allí que las incidencias fueran registradas en un cuaderno de campo donde se reflejaron todas las impresiones y reflexiones sobre lo escuchado y presenciado del momento, así como aquellas notas metodológicas vinculadas a las características de las dinámicas de cada una de las acciones propuestas para desarrollarse en la fase No 1. Se elaboró a partir de allí lo que se denomina: "cuadro de categorización" en el que se fueron asentando cada uno de estos episodios y las correspondientes categorías con el propósito de ir generando los conceptos definitorios de las acciones registradas, realizando luego la aplicación del método de comparación constante de los incidentes.

Estos acontecimientos o eventualidades se fueron analizando línea por línea, identificando sus propiedades, explorando sus interrelaciones, logrando así integrarlos en una categoría de cuya dimensión, tal y como lo expresan Strauss y Corbin (2002) se lograra: "hacer codificación renglón por renglón (...) porque le permite al analista generar categorías rápidamente y desarrollarlas por medio de un muestreo adicional" de allí a establecer una reflexión como resultado de las incidencias en el que se guarda una lógica razonable. El proceso, denominado: método de comparación constante fue el que viabilizó el establecimiento de reflexiones acerca de la investigación. Ejemplo de ello se expresa en el fragmento de cuadro de categorización de la acción No 1 en la primera fase expresado en la tabla No 1 :

\section{Ejecución de la Acción No 1: Estadio de la percepción}

La actividad dio inicio el 13 de julio de 2019 en el patio central del Edificio San José de la Universidad de Los Andes a las 8:00am, la misma culminó a las 12:00m.

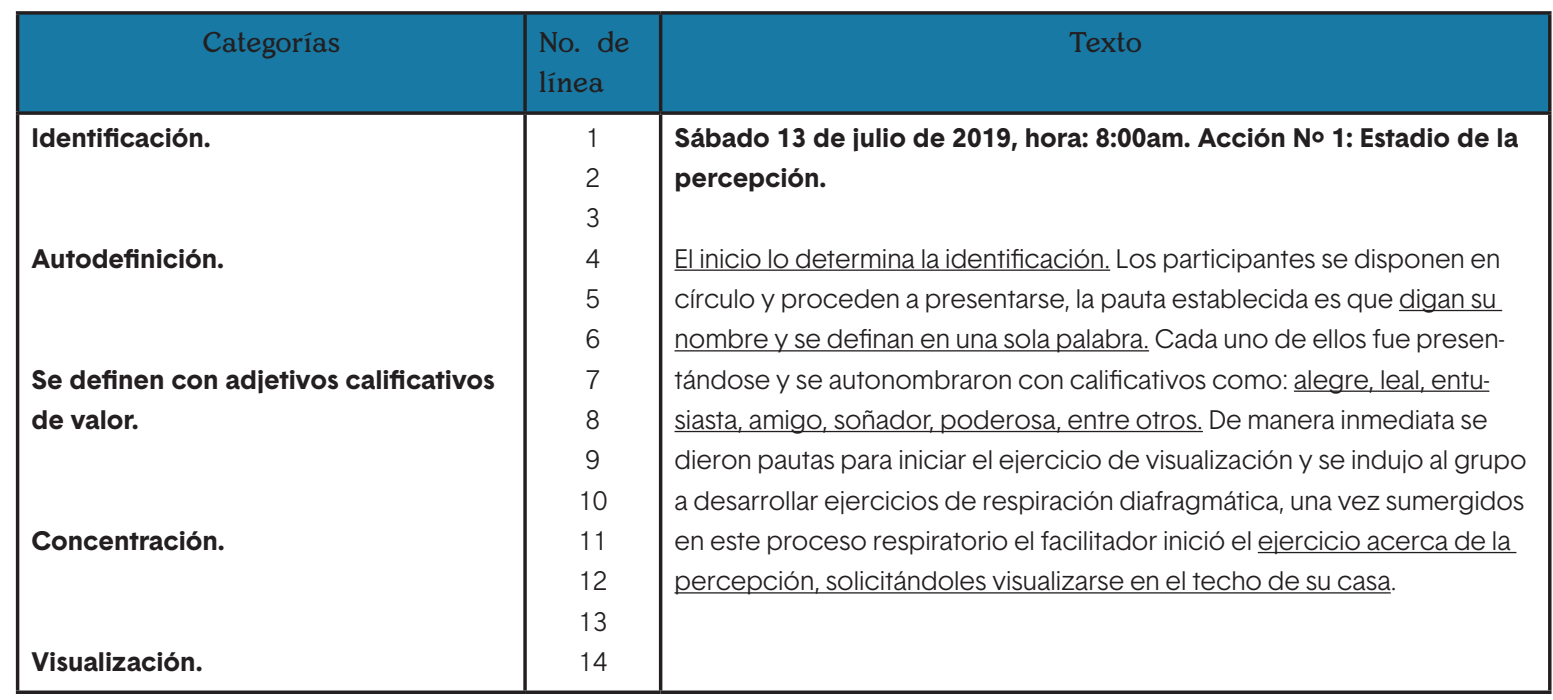

Tabla No 1: fragmento del cuadro de categorización de la Fase No 1. Fuente: El autor (2019). 
Una vez identificado el grupo se plantearon las primeras instrucciones solicitando a los participantes disponerse a las acciones de juego como una experiencia para el autoreconocimiento. La primera acción de la Fase No 1 se denominó "el estadio de la percepción": un primer paso para comprender el entorno que nos rodea desde una premisa enmarcada en una reflexión de Maurice Ponty (1945): "El cuerpo está en el mundo como el corazón en el organismo: mantiene continuamente en vida el espectáculo visible, lo anima y lo alimenta interiormente, forma con él su propio universo" (p. 219).

A partir de esta premisa la práctica invitó a dar un paseo por el autoreconocimiento del cuerpo tras estadios respiratorios visualizándose en la tierra, en un movimiento constante, luego en vuelo, dando rienda suelta a la imaginación. El ejercicio se condujo por la visualización; imaginándose en vuelo, sentir el aire, respiraciones profundas, con alas imaginarias, elevándose a las alturas. La acción continuó entonces con el reconocimiento de las manos y sus posibilidades expresivas, desplazamientos y movimientos corporales, ilustración de imágenes a través del lenguaje corporal, materialización de objetos imaginarios y transformación de los objetos.

\section{Ejecución de la Acción No 2: Estadio de la imaginación}

La actividad se desarrolló el 13 de julio de 2019 en el patio central del Edificio San José de la Universidad de Los Andes de 2:00 a 6:00pm. Los participantes retomaron la disposición inicial y las respiraciones profundas. El estadio de la imaginación dio apertura con una frase de Caillois (1986): El sujeto olvida, disfraza, despoja pasajeramente su personalidad para fingir otra (p. 52). La pauta que se estableció fue abrirse a un espacio de improvisación.

Luego se invitó a los participantes a movilizarse respondiendo a pautas muy específicas pero desarrollando la acción a su manera, así que se propusieron ejercicios como: desplazarse por el lugar con urgencia, tropezarse y establecer una comunicación visual con el otro, disculparse sin hacer uso de la palabra, saludarse afectivamente, abrazarse, acompañar a alguno tomándolo de la mano sin el uso de la palabra hablada, continuar caminando, esta vez con el objetivo de llegar a un lugar desconocido. Todos los ejercicios fueron conducentes a abrir la puerta a desarrollos inesperados de relaciones humanas en el aquí y el ahora, el camino idóneo para ser uno mismo a partir de premisas o códigos de acción y para ser otro desde la imaginación, este espacio se dispuso a la apertura de procesos creativos.

A partir de esta premisa el grupo desarrolló acciones sobre caminar por situaciones simuladas, acciones cotidianas a través del gesto, acciones preestablecidas a partir de palabras estimuladoras (navegar, conducir, nadar, volar, pilotear, entre otras) y palabras estimuladoras con el apoyo de un compañero. Se realizaron ejercicios orientados al mundo imaginario en colectivo; carreras en diferentes tiempos y andar y relacionarse a partir de diferentes características físicas, situaciones de representación fundamentadas en el imaginario simulando caracteres diversos en el caminar, acciones que al ejecutarse fueron conduciendo a los participantes a comprender su cuerpo como un todo expresivo.

Se incorporó posteriormente el elemento musical en vivo, una flautista (imagen 1), con el propósito de que los ejecutantes escucharan el sonido y lo integraran como una fracción de su ejercicio individual y colectivo. La premisa inicial fue que los participantes respondieran con improvisaciones corporales a partir de las sensaciones generadas por la melodía, pero de manera imprevista se percibió que la ejecutante musical se involucró en el proceso respondiendo musicalmente a las formas corporales de los intérpretes.

\section{Ejecución de la Acción № 3: Estadio de la comunicación}

La actividad dio inicio el 20 de julio de 2019 en el patio central del Edificio San José de la Universidad de Los Andes a las 8:00am a 12:00m. El estadio de la comunicación abrió la puerta a establecer relaciones y alianzas en el juego, se orientaron las acciones tomando como premisa una idea expresada por Habermas (1992) en su "Teoría de la acción comunicativa" a partir del planteamiento de 


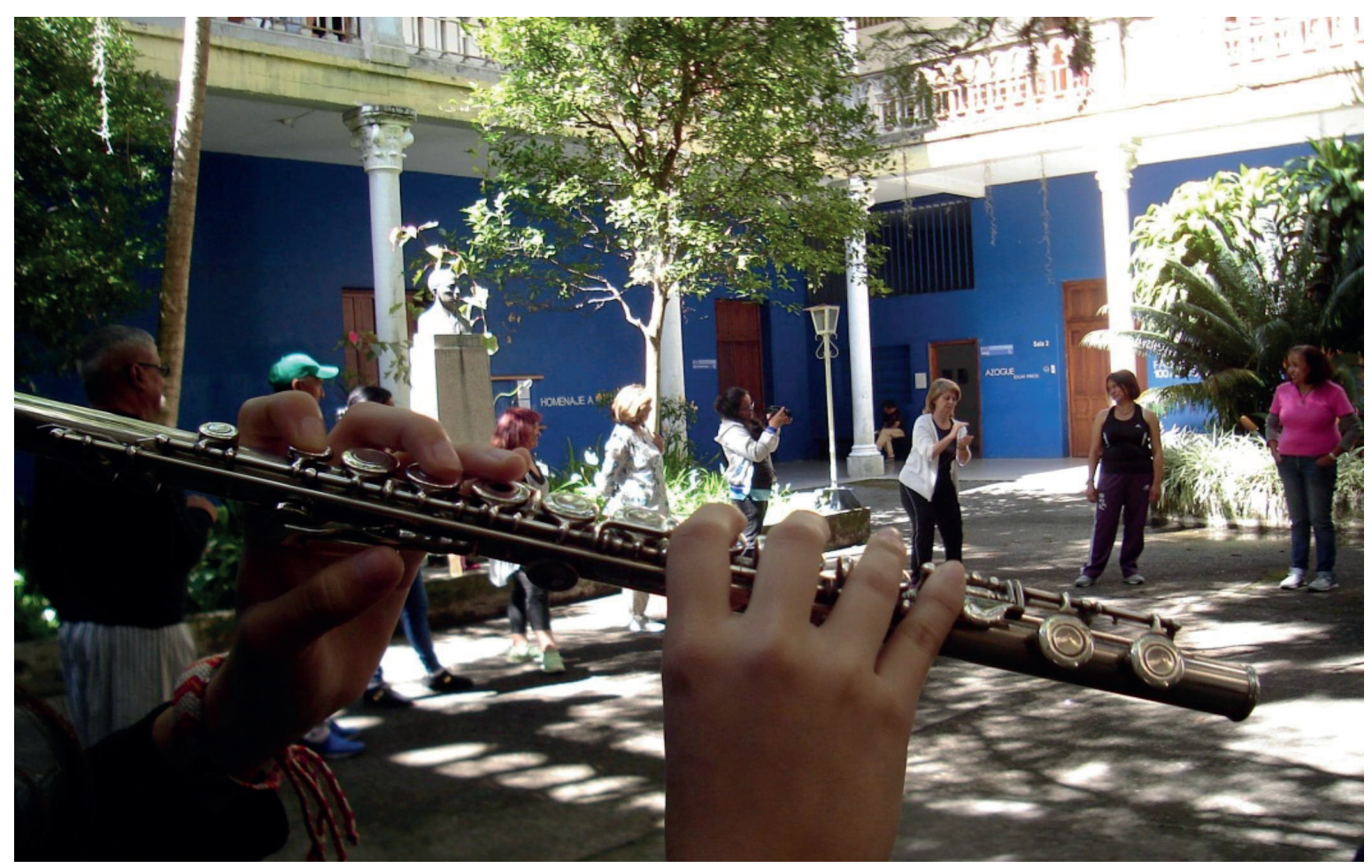

Ilustración 1. Los participantes integran el sonido de la flauta como una fracción del ejercicio. Fuente: Rossana Toro (2019).

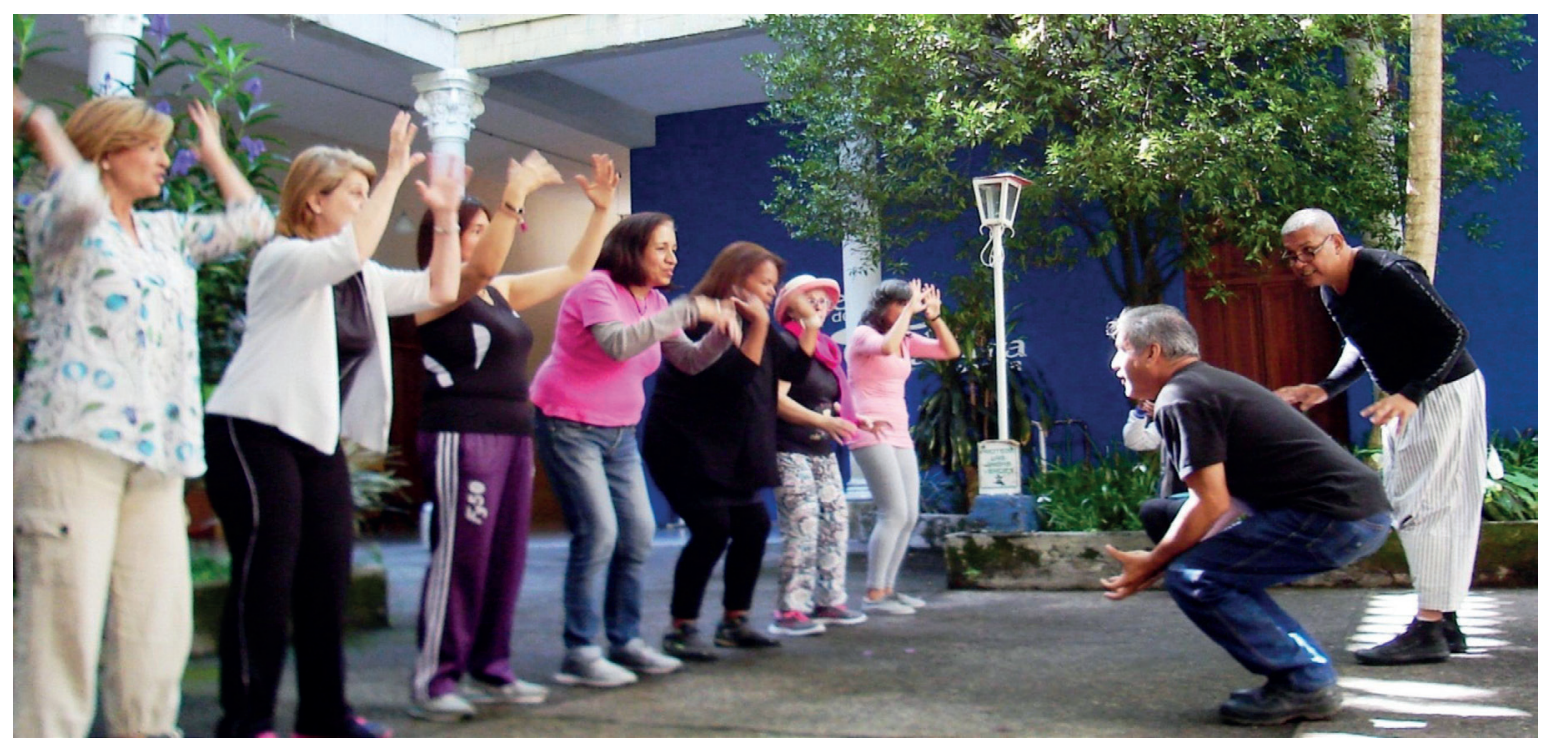

Ilustración 2. Vista dela acción de mensajes emitidos con un idioma inventado determinando acciones comunicativas meramente gestuales. Fuente: Rossana Toro (2019). 
Mead sobre la comunicación: “(...) las señales están insertas de tal modo en los contextos de acción que sirven siempre para coordinar acciones de los distintos participantes en el sentido cuasiindicativo y en el sentido cuasi - expresivo con su sentido cuasi - imperativo. (p. 14). A partir de esta idea se propusieron acciones de imitación, de movimiento liderando la situación grupal, de determinación de un lenguaje verbal único de creación propia, donde el gesto y la emoción prevalecen para comunicarse (imagen 2), de emisión de sonidos con diferentes registros, de mensajes emitidos con un idioma inventado determinando acciones comunicativas meramente gestuales.

La dinámica a continuación se orientó hacia la comprensión de la comunicación como una expresión humana fundamental para el desarrollo de actividades creativas, por lo que se plantearon ejercicios sobre comunicación verbal y no verbal con fines de elaborar discursos individuales y colectivos tales como: construcción de discursos coherentes aportando individualmente una palabra o sílaba, contar historias improvisadas sin el uso de la palabra a partir de la referencia de imágenes, luego una socialización de la actividad realizada enfocada a discernir acerca de lo que se hizo, se aprendió y quedó como aprendizaje de lo vivenciado.

\section{Ejecución de la Acción No 4: Estadio de la expresión}

La actividad se desarrolló el 20 de julio de 2019 en el patio central del Edificio San José de la Universidad de Los Andes de 2:00 a 6:00pm. En el estadio de la expresión cada participante, apoyado en su experiencia previa del laboratorio expresó con libertad la creación de un cuento a partir de una imagen establecida construyéndola luego en colectivo. La historia se adhirió a la corporeidad del participante por lo que emergieron personajes característicos que caminaban con circunstancias e historias propias que iban generando conflictos internos para luego abrirse a conflictos de situación. La actividad inició con la premisa de una idea expresada por Marzán (1999) la cual afirma: "El juego constituye la puesta en escena de un excedente de fuerzas que caracteriza a todo cuanto tiene vida" (p. 315). Lo que condujo al desarrollo de acciones sobre "mímesis".
El facilitador indicó a los participantes disponerse frente a él en línea horizontal. Valiéndose de un equipo de sonido y pistas sobre diferentes géneros musicales, pidió realizar a cada participante, según el tema musical que se iba escuchando, fingir ser el intérprete de la misma haciendo un doblaje del tema, por lo que cada uno de ellos improvisó ser un intérprete de ópera, rock, balada, bolero u otros géneros musicales. Se realizaron ejercicios de improvisación con estas mismas características el resto de la jornada.

\section{Resultados}

Esta primera fase del Laboratorio del juego constituyó un paso introductorio de una investigación en cuya experiencia "el juego" se estableció como un vehículo para generar caminos de libertad, expresividad y espontaneidad a través de dinámicas expresivas y ejercicios de juego escénico en los que se pudieran establecer momentos de auto reconocimiento y verdaderos vínculos de comunicación entre unos y otros.

Se trató de una encrucijada en la que se abrió una puerta creativa para comprender la relevancia de la madurez emocional y generar procesos creativos, de afinidad, respeto y comunicación irrepetibles entre adultos mayores, un espacio enfocado en la intención de contribuir a que el participante vivenciara la posibilidad de dar lo mejor de sí mismo, no siendo niños, pero si jugando en la adultez en una práctica en la que fueron capaces de transmitir lecciones valiosas, formando relaciones de agrado y plenitud, tal y como lo expresa la psicología positiva de la que Park, N., Peterson, C. y Sun, J. (2013) sostienen que: "la vida implica algo más que evitar o resolver problemas y que las explicaciones de lo que es una buena vida debe hacer más que centrarse en el reverso de los problemas." (p. 12).

Los cuatro estadios de la fase No 1 reflejaron: disposición para el trabajo colectivo; en la medida en que los participantes se fueron sintiendo cada vez más cómodos, con mayor confianza y familiarizados como grupo, concentración para el desempeño de las acciones; lo que evidenció compromiso por parte de cada uno de ellos por entregarse a la experiencia y aprovecharla al 
máximo, capacidad expresiva; por cuanto la expresión llegó a ser libre y auténtica, una vez vencido el miedo escénico y la inseguridad de exponerse ante los demás, reconocimiento del cuerpo como fuerza creativa; dado que hubo mayor conciencia de las posibilidades para expresarse y relacionarse entre sí y mayor disposición por alcanzar metas y generar proyectos para el futuro; lo que se evidenció una vez socializada la experiencia y a partir del autoreconocimiento como seres más expresivos y comunicativos.

Incorporar música en vivo por medio de la ejecución de una flautista motivó a los participantes a desarrollar formas gestuales con un sentido más coreográfico y elaborado y, más allá de esto, en la intérprete musical, sin haber sido previsto, se produjo la motivación por crear efectos sonoros que terminaron acompañado la expresividad de los participantes hacia una nueva posibilidad de juego. Esta práctica evidenció que no existe acto creativo donde no intervengan procesos de percepción, comunicación y libre expresión como estímulos para generar nuevas propuestas y proyectos una vez que las personas reconocen sus potencialidades y sus alcances.

Cada uno de los partícipes de la experiencia culminó la experiencia con una profunda motivación y grandes expectativas por seguir vivenciando momentos como estos, lo fundamental es el caudal de potencialidades que se reconocieron como parte del Laboratorio del Juego. De allí que en la socialización final se llegaran a reflexiones que expresan que hubo mucha timidez por encarar el laboratorio, pero que en la medida en que se avanzaba en el proceso, se fue reconociendo la habilidad de percibir el entorno, la manera de captar todas las formas y la afirmación de las potencialidades humanas.

A partir de este momento se enunciaron apreciaciones que han resultado fundamentales para la investigación por cuanto se manifestó la importancia de apreciar el talento que cada participante aportó a la experiencia, entrega en el universo expresivo de cada acción, reconocimiento de la risa y la alegría como emociones motivadoras, de "el juego" como una herramienta poderosa para comunicarse que viabiliza con facilidad esta condición humana y necesidad de emprender nuevos proyectos de vida.

\section{Conclusiones}

Lo que este artículo presenta es apenas un punto de partida, la primera fase del Laboratorio del Juego como un acercamiento al autoreconocimiento y reemprendimiento de adultos mayores en el rango entre los 60 y 70 años de edad de una comunidad de la ciudad de Mérida, Venezuela, a partir de una experiencia creativa fundamentada en la instintividad del juego de la infancia, de allí que se llevaran adelante las acciones por medio de ejercicios de juego escénico, las cuales ciertamente incorporaron a todos a una vivencia única de "juego".

Un grupo de participantes que se visualizaban en el cese de su actividad laboral fructífera, así como en el final del camino de la productividad por lo que llegaron a visualizarse en el camino del sedentarismo y el deterioro. Pero ¿Cómo hacer posible a través de un proyecto de investigación acerca de "el juego" dirigido al adulto mayor, la procura de un espacio de bienestar psicológico, encaminando emociones positivas hacia la productividad, la creatividad, el fortalecimiento de la inteligencia emocional, reconociendo las virtudes y fortalezas que se tienen en función de reemprender?

La experiencia posibilitó, no sólo la elaboración de un plan de acciones de juego escénico a favor de estos propósitos, sino a hacer posible que los participantes vivenciaran ejercicios orientados al desarrollo de la percepción, imaginación, comunicación y expresión y valoraran el recorrido de esta práctica en un espacio creativo, formativo y de autoreconocimiento de potencialidades para crecer como personas al visualizar nuevos emprendimientos.

La investigación, tal y como se propuso en los objetivos de la investigación, fue sistematizando y codificando las incidencias con el propósito de tener un registro escrito y en formato de video digital de la experiencia a manera de interpretar lo sucedido y poder reflexionar sobre los alcances de una propuesta de estas características y su desarrollo en el presente. Finalmente, el desarrollo del proyecto de 


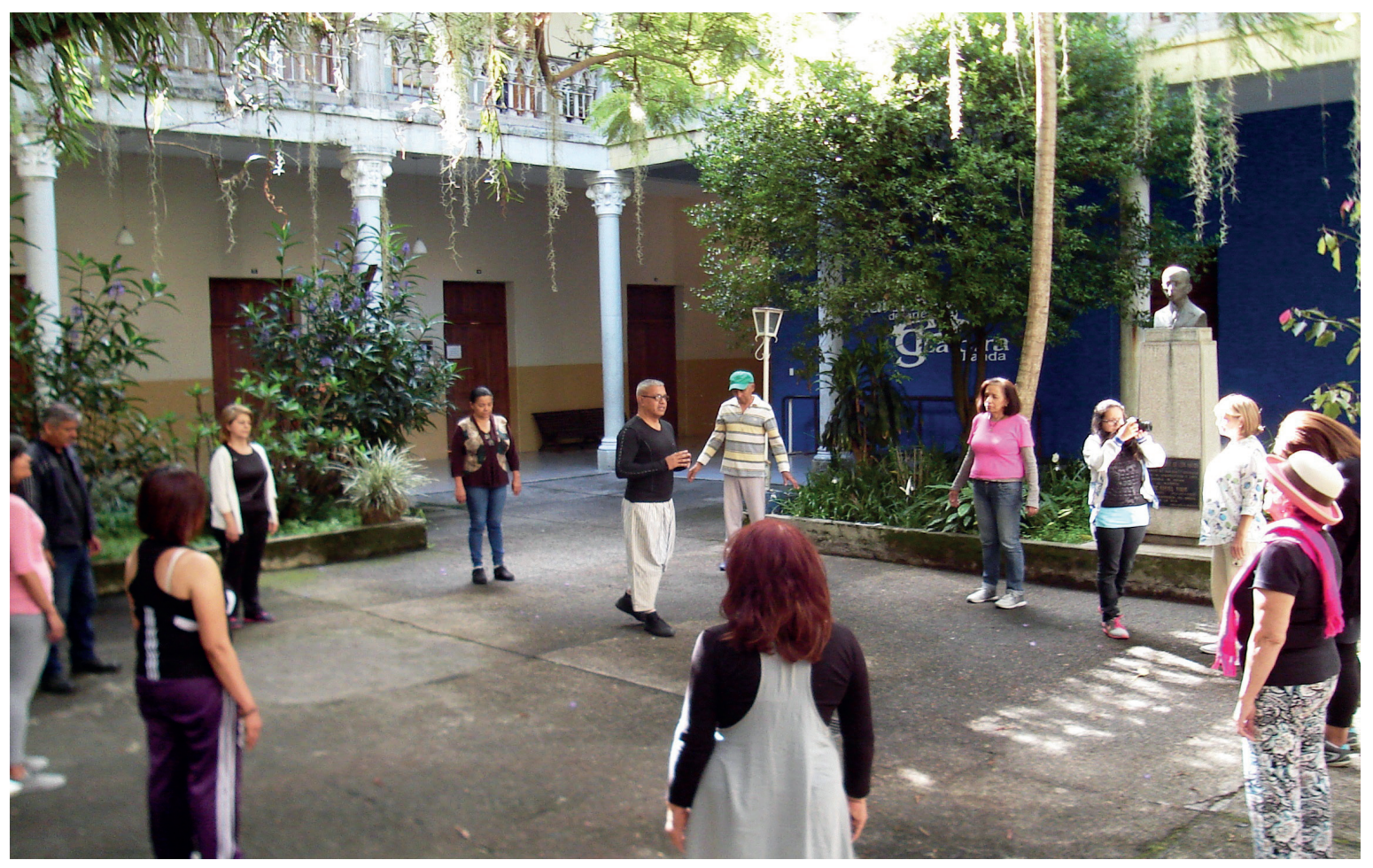

Ilustración 3. Estadio de la percepción. Registro de procesos (2021). Fuente: Rossana Toro.

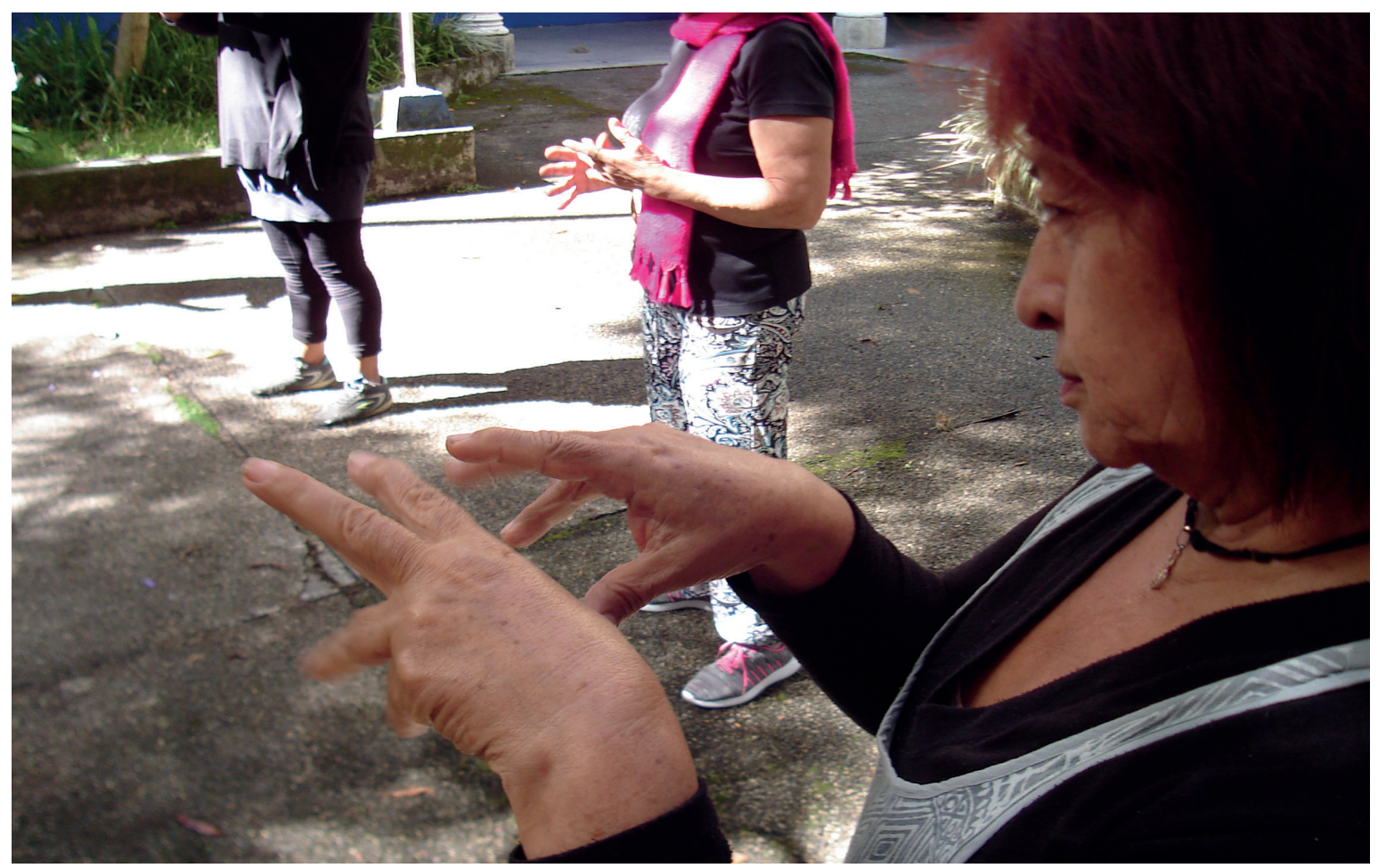

Ilustración 4. Reconocimiento de las manos como potencial expresivo. Registro de procesos (2021). Fuente: Rossana Toro 
investigación culminó en la apertura a la reflexión y a la generación de lo que se denominó: observatorio social de la experiencia, de allí la relevancia de elaborar un material audiovisual que expresó lo vivenciado con expectativas de proyección en redes sociales e institucionales.

\section{Referencias}

Argullol, L. (1991). La actualidad de lo bello. El arte como o juego, símbolo y fiesta. Introducción. El arte después de la «muerte del arte». Barcelona: Ediciones Paidós. I.C.E. de la Universidad Autónoma de Barcelona.

Caillois, R. (1986). Los juegos y los hombres La máscara y el vértigo. México: Colección Fondo de cultura económica.

Gadamer, H. (1991). La actualidad de lo bello. El arte como o juego, símbolo y fiesta. Barcelona: Ediciones Paidós. I.C.E. de la Universidad Autónoma de Barcelona.

Gelvis, J. (2017). La mimesis aristotélica y platónica en la poesía contemporánea. Revista IGNIS, 3. Recuperado de: «file:///C:/Users/lgor/Downloads/1468-Texto\%20del\%20 art\%C3\%ADculo-3901-1-10-20170713.pdf» [Fecha de consulta: marzo 28 de 2020]

Habermas (1992). Teoría de la Acción Comunicativa. Madrid, España: Taurus Ediciones.

Huizinga, J. (2007). Homo Ludens. Madrid, España: Historia Alianza editorial/Emecé editores.

Jiménez, V. (2011). Psicología positiva. In book: Psicología contemporánea básica y aplicada, Ediciones pirámide, pp.567-589 Recuperado de: «https://www.researchgate. net/publication/266733984_Psicologia_Positiva» [Fecha de consulta: noviembre 16 de 2019]

Lorca, O. (2005). Arte, juego y fiesta en Gadamer. En A Parte Rei: revista de filosofía, 41. ISSN 1137-8204, ISSN-e 2172-9069. Recuperado de: «http://serbal.pntic.mec.es/ cmunoz11/lorca41.pdf» [Fecha de consulta: marzo 22 de 2019]

Marzán, C. (1999). Sobre el concepto del juego en Gadamer. Laguna: Revista de Filosofía, 6, pp. 315-318. Recuperado de: «https://dialnet.unirioja.es/servlet/ articulo?codigo=172297» [Fecha de consulta: mayo 03 de 2019]

Padrón, J. (2001). La Estructura de los procesos de investigación. Revista educación y ciencias humanas, IX,(17). Recuperado de: «http://padron.entretemas.com.ve/Estr_ Proc_Inv.htm » [Fecha de consulta: marzo 18 de 2019]

Park, N., Peterson, C. y Sun, J. (2013). La psicología positiva, investigación y aplicaciones. Recuperado de: «https://scielo.conicyt.cl/scielo.php?script=sci_arttext\&pid=S0718-48082013000100002» [Fecha de consulta: febrero 16 de 2020]

Ponty, M. (1945). Fenomenología de la percepción. Proyectos Editoriales y Audiovisuales CBS, S.A. Ríos, M. (2012). Johan Huizinga (1872-1945): Ideal caballeresco, juego y cultura. México, Revista Casa del Tiempo, 9. Recuperado de: «http://www.uam.mx/difusion/casadeltiempo/09_iv_jul_2008/casa_del_tiempo_elV_num 09_71_80.pdf » [Fecha de consulta: enero 22 de 2020]

Schettini, P. y Cortazzo, I. (2015). Análisis de datos cualitativos en la investigación social. Procedimientos y herramientas para la interpretación de información cualitativa. Facultad de Trabajo Social. Universidad de La Plata. EDULP Editorial de la Universidad de La Plata. Recuperado de: «https://libros.unlp.edu.ar/index.php/unlp/catalog/ download/451/416/1497-1»

Seligman, M. (2006). La auténtica felicidad. Barcelona, España: Ediciones B, S. A.

Strauss, A. y Corbin, J. (2002). Bases de la investigación cualitativa. Técnicas y procedimientos para desarrollar la teoría fundamentada. Colombia: Universidad de Antioquía. 